\title{
CONQUISTAS NA CARREIRA DOCENTE DE EGRESSAS DO CURSO DE PEDAGOGIA/PARFOR/SERRINHA-BA: PERCEPÇÕES SOBRE OS PROCESSOS DE DESENVOLVIMENTO PROFISSIONAL
}

\author{
Erica de Jesus Santos ${ }^{1}$ \\ Ivonete Barreto de Amorim² \\ Sandra Célia Coelho Gomes da Silva ${ }^{3}$
}

${ }^{1}$ Universidade do Estado da Bahia (UNEB) Campus XI, Serrinha, BA, Brasil.
${ }^{2}$ Universidade do Estado da Bahia (UNEB) Campus XI, Serrinha, BA, Brasil.
${ }^{3}$ Universidade do Estado da Bahia (UNEB) Campus XII, Guanambi, BA, Brasil.

Resumo: O presente artigo intitulado Conquistas na carreira docente de egressas do curso de Pedagogia/Parfor/Serrinha-BA: percepções sobre os processos de desenvolvimento profissional, que teve como objetivo elencar as conquistas concernentes à carreira docente de egressas do curso de Pedagogia/PARFORSerrinha-BA que emergiram dos processos de desenvolvimento profissional. O referencial teórico foi ancorado nas contribuições de: Amorim e Ribeiro. (2018), Day (2001), Gatti e Barreto (2009), Minayo (2000), Nóvoa (2009), Ramalho et al. (2014). O caminho metodológico consistiu em uma pesquisa qualitativa, tendo como instrumento de coleta de informações a entrevista narrativa, das quais emergiram três categorias, a seguir: compreensão acerca do desenvolvimento profissional docente, conquistas da formação na atuação docente, perspectivas de novas conquistas no desenvolvimento profissional. Conclui-se que é veementemente importante o profissional da educação estar em constante formação para assim melhorar suas práticas e realizações, tanto pessoais quanto profissionais. Contudo, a profissionalização do educador é essencial, uma vez que ele é o sujeito capaz de fazer transformações na vida dos sujeitos envolvidos no processo de aprendizagem.

Palavras-chave: Pedagogia. Narrativas. Desenvolvimento profissional. Parfor.

\begin{abstract}
This article entitled Achievements in the teaching career of graduates of Pedagogy / Parfor / SerrinhaBA: perceptions about the processes of professional development, which aimed to list the achievements concerning the teaching career of graduates of Pedagogy / PARFOR-Serrinha -BA that emerged from the professional development processes. The theoretical framework was anchored in the contributions of: Amorim and Ribeiro. (2018), Day (2001), Gatti and Barreto (2009), Minayo (2000), Nóvoa (2009), Ramalho et al. (2014). The methodological approach consisted of a qualitative research, using narrative interview as an instrument for collecting information, from which three categories emerged, as follows: understanding about teacher professional development, achievements in teacher education, prospects for new achievements in professional development. It is concluded that it is vitally important for education professionals to be in constant training to improve their practices and accomplishments, both personal and professional. However, the professionalization of the educator is essential, since he is the subject capable of making changes in the lives of the subjects involved in the learning process.
\end{abstract}

\footnotetext{
Apoio financeiro: Nenhum.

Conflitos de interesses: Os autores declaram não haver nenhum conflito de interesse.

Correspondência: ivoneteeducadora@hotmail.com

Recebido: 30 Mar 2020.

Aprovado: 25 Mai 2020

Editor: Marcelo Máximo Purificação.
}

Este é um artigo publicado em acesso aberto (Open Access) sob a licença Creative Commons Attribution, que permite uso, distribuição e reprodução em qualquer meio, sem restrições desde que o trabalho original seja corretamente citado. 
Key-words: : Pedagogy. Narratives.Professional development. Parfor.

Como citar: SANTOS, E. J; AMORIM, I. B; SILVA, S. C. C. G. Conquistas na carreira docente de egressas do Curso de Pedagogia/Parfor/Serrinha-BA: percepções sobre os processos de desenvolvimento profissional. Revista Científica Novas Configurações - Diálogos Plurais, Luziânia, v. 1, n.1, p. 71-79, 2020. https://doi.org/.10.4322/2675-4177.2020.010

\section{INTRODUÇÃO}

A presente pesquisa é fruto de investigação vinculado ao grupo de pesquisa: Educação, Políticas Públicas e Desenvolvimento Social, que motivou o projeto de Iniciação Cientifica "Egressas do Curso De Pedagogia do Parfor/Serrinha-BA: Diálogos Sobre O Desenvolvimento Profissional", vinculado à Universidade do Estado da Bahia (UNEB), Departamento de Educação, Campus XI-Serrinha, do qual emergiu o subprojeto "Conquistas na Carreira Docente de Egressas do Curso de Pedagogia/Parfor/Serrinha-BA: Percepções Sobre Os Processos De Desenvolvimento Profissional, ora apresentado neste artigo (IC/CNPq).

Destarte, é relevante desvendar os percursos do desenvolvimento desse estudo. Com base no levantamento de estudos existentes nos últimos cinco anos no Colegiado de Pedagogia UNEB-Campus XI, foram encontradas uma monografia e uma dissertação no repositório da UFBA que enfatizaram questões acerca da atuação docente que a pedagogia possibilita sobre a formação do professor, mas não dão foco necessário sobre Desenvolvimento Profissional docente das egressas do Curso de Pedagogia/Parfor/Serrinha-BA, dentre as quais destacamos no quadro 1 e 2 a seguir.

Quadro 01. Relação de monografia: sobre a formação do professor

\begin{tabular}{|c|c|c|c|c|}
\hline IDENTIFICAÇÃO & AUTOR & ANO & TÍTULO & OBJETIVO GERAL \\
\hline Monografia & $\begin{array}{l}\text { SILVA, Thayane M. } \\
\text { Carvalho. }\end{array}$ & 2015 & $\begin{array}{llr}\text { Repercussões } & & \text { da } \\
\text { formação e da } & \text { não } \\
\text { formação } & & \text { de } \\
\text { professores em } & \text { suas } \\
\text { práticas pedagógicas. }\end{array}$ & $\begin{array}{l}\text { Compreender como a } \\
\text { formação docente } \\
\text { influencia em suas } \\
\text { práticas pedagógicas. }\end{array}$ \\
\hline
\end{tabular}

Fonte: produção encontrada no Colegiado de Pedagogia, Campus XI, 2019.2

Quadro 02. Relação de dissertação: sobre formação de professoras da Parfor.

\begin{tabular}{|c|c|c|c|c|}
\hline IDENTIFICAÇÃO & AUTOR & ANO & TÍTULO & OBJETIVO GERAL \\
\hline Dissertação & $\begin{array}{l}\text { PORTELA, Regina } \\
\text { Lúcia dos Santos. }\end{array}$ & 2019 & $\begin{array}{l}\text { Os ministérios de } \\
\text { Clarice: narrativas de } \\
\text { professoras egressas da } \\
\text { primeira turma do } \\
\text { curso de Licenciatura } \\
\text { em Pedagogia do } \\
\text { Parfor UFBA sobre a } \\
\text { formação. }\end{array}$ & $\begin{array}{lr}\text { Compreender } & \text { a } \\
\text { percepção } & \text { de } \\
\text { professoras sobre } & \text { a } \\
\text { formação docente, a } & \text { artir de uma política } \\
\text { educacional situada, o } & \text { plano Nacional } \\
\text { formação de } \\
\text { professores } & \text { de } \\
\text { Educação } & \text { Básica } \\
\text { (PARFOR), } & \text { por } \\
\text { entender } & \text { sua } \\
\text { especificidade } & \text { em } \\
\text { formar docentes que } \\
\text { atuam na rede pública } \\
\text { da educação básica. }\end{array}$ \\
\hline
\end{tabular}

Fonte: produção encontrada no repositório da UFBA. 2019.2

A pesquisa de Portela (2019) consistiu no levantamento bibliográfico sobre egressos do Parfor, articulado às discussões teóricas sobre a formação docente e os elementos que constituem o profissional docente, apresentando subsídio valioso para compreender a formação docente e sua repercussão na maneira como entendemos a educação hoje. Esta pesquisa teve por objetivo compreender a percepção de professoras sobre a formação docente, concluindo que, para viabilizar a voz de professoras sobre como percebem seus processos formativos em articulação a suas práticas, assume a potencialidade reflexiva, caracterizada como uma dimensão da profissão docente, elemento estruturante para se pensar as políticas públicas educacionais sob a ótica de quem as vivencia, evidenciando assim, suas necessidades a partir da própria experiência.

A respectiva pesquisa de Silva (2015) discutiu sobre a formação e da não formação de professores em suas práticas pedagógicas, trazendo à discussão a importância da formação continuada e do Parfor para esses profissionais. Desta maneira, o objetivo geral vem com a perspectiva de compreender 
como a formação docente influencia em suas práticas pedagógicas, e partindo dessa premissa, o respectivo trabalho visou a compreensão acerca da formação docente de professores que não possuíam a formação específica na área em que atuavam e assim entender as suas práticas pedagógicas. Com isso, é válido refletir sobre a aura que a formação e a prática de ensino tem na vida profissional de um professor, sendo este o principal agente transformador da vida de seus alunos.

Essas pesquisas trouxeram importantes contribuições para o campo da formação docente, contudo não invalida investigar a seguinte questão de pesquisa: Quais conquistas concernentes à carreira docente de egressas do curso de Pedagogia/PARFOR emergiram dos processos de desenvolvimento profissional? E como objetivo: elencar as conquistas concernentes à carreira docente de egressas do curso de Pedagogia/PARFOR-Serrinha-BA que emergiram dos processos de desenvolvimento profissional.

Diante dessas considerações iniciais, o artigo ficou estruturado em três seções: caminho metodológico; análise e discussão dos resultados da pesquisa e, por fim, as considerações finais.

\section{CAMINHO METODOLÓGICO}

O caminho metodológico desta investigação esteve voltado para a consecução de um objetivo específico do projeto maior que foi elencar e analisar as conquistas concernentes à carreira docente de egressas do Curso de Pedagogia/PARFOR-Serrinha-BA, que emergiram dos processos de desenvolvimento profissional. Para tanto, optamos por uma pesquisa qualitativa, a qual trabalha com um nível de realidade avesso à quantificação, ou seja, o universo de significados, motivos, aspirações, crenças, valores e atitudes que corresponde a um espaço mais profundo das relações, dos processos e dos fenômenos e que não pode ser reduzido à operacionalização de variáveis (MINAYO, 2000).

É oportuno salientar que a pesquisa qualitativa nos permite dar uma significância maior ao contexto em que a investigação se insere e o estado em que se encontram os sujeitos, como os sentidos e significados subjetivamente narrados. Com base nessa premissa, escolhemos como procedimento para a de coleta de informações a entrevista narrativa, que foi realizada com egressas do Curso de Licenciatura em Pedagogia/ PARFOR-Serrinha-BA.

Esse tipo de entrevista repousa sobre alguns postulados. O primeiro considera a entrevista como uma narração, o que significa dizer que ela comporta uma unidade de sentido e que seus componentes devem ser considerados como partes interligadas de um conjunto, na perspectiva de não se perder o sentido que os participantes dão às suas palavras. O segundo postulado considera que a perspectiva do outro tem sentido, ou seja, o participante é um sujeito ativo que atribui sentido à sua ação num processo de interação. O terceiro postulado, sobre o qual repousa a entrevista, compreende a natureza da realidade como um processo em permanente mudança. Após coleta dessas informações, foi efetivada uma leitura exaustiva de todo material, com vistas à exploração do material, o tratamento dos resultados, a inferência e a interpretação.

Importante destacar que o contexto que respaldou a escolha das colaboradoras da pesquisa foi o Departamento de Educação da Universidade do Estado da Bahia/Campus XI, do qual originou a formação das professoras, especificamente, no Curso de Pedagogia do Plano de Nacional de Formação de Professores da Educação Básica - Plataforma Freire (PARFOR).

As colaboradoras da pesquisa foram quatro professoras da Educação Básica do Território do Sisal, egressas do PARFOR/Serrinha-BA, escolhidas via grupos de WhatsApp do PARFOR; ao confirmarem interesse em participar da pesquisa, foram convidadas a fazerem as entrevistas em horário e local marcados previamente, assinaram o Termo de Consentimento Livre e Esclarecido (TCLE), ressaltando que estas professoras autorizaram a gravação das entrevistas e receberam nomes fictícios, a citar:

Quadro 02: Caracterização das colaboradoras da pesquisa.

\begin{tabular}{|l|l|l|l|l|l|l|}
\hline Colaboradora & Idade & Formação & Carga horária & Pós-graduação & $\begin{array}{l}\text { Tempo de } \\
\text { atuação }\end{array}$ & Ano que atua \\
\hline Chica & 49 & $\begin{array}{l}\text { Magistério/ } \\
\text { Licenciatura em } \\
\text { Pedagogia }\end{array}$ & $\begin{array}{l}\text { Horas. } \\
\text { Psicopedagogia. }\end{array}$ & 23 anos & $\begin{array}{l}\text { Educação } \\
\text { infantil }\end{array}$ \\
\hline
\end{tabular}




\begin{tabular}{|c|c|c|c|c|c|c|}
\hline Maria & 38 & $\begin{array}{ll}\text { Magistério/ } \\
\text { Licenciatura em } \\
\text { Pedagogia }\end{array}$ & 40 horas & Não. & 16 anos & $\begin{array}{l}\text { Educação } \\
\text { Infantil como } \\
\text { cuidadora de } \\
\text { criança } \\
\text { Autista e } \\
\text { Síndrome de } \\
\text { Down. }\end{array}$ \\
\hline Laura & 51 & $\begin{array}{l}\text { Magistério/ } \\
\text { Licenciatura em } \\
\text { Pedagogia }\end{array}$ & 40 horas & $\begin{array}{l}\text { Iniciou, mas não } \\
\text { concluiu. }\end{array}$ & 13 anos & $\begin{array}{l}\text { Está atuando } \\
\text { como } \\
\text { coordenadora } \\
\text { da educação } \\
\text { Infantil na } \\
\text { Secretaria de } \\
\text { Educação do } \\
\text { município. }\end{array}$ \\
\hline Luiza & 31 & $\begin{array}{l}\text { Magistério/ } \\
\text { Licenciatura em } \\
\text { Pedagogia }\end{array}$ & 40 horas & $\begin{array}{lr}\text { Fez, mas } & \text { não } \\
\text { pegou } & \text { o } \\
\text { certificado. } & \end{array}$ & 20 anos & $\begin{array}{l}\text { Está atuando } \\
\text { como } \\
\text { Coordenadora } \\
\text { dos anos } \\
\text { iniciais na } \\
\text { Secretaria de } \\
\text { Educação do } \\
\text { município. }\end{array}$ \\
\hline
\end{tabular}

. A professora Maria possui formação em Magistério e Pedagogia, com dezesseis anos de docência, atua como cuidadora numa turma de Educação Infantil, da rede municipal, acompanhando uma criança com Síndrome de Down e outra autista. Durante a entrevista, a professora demonstrou alegria com as aprendizagens das suas crianças, enfatizando bastante o conhecimento adquirido durante o curso, que lhe possibilitou ter uma visão ampla de como trabalhar na Educação Infantil.

A professora Chica possui formação em Magistério e Pedagogia e Pós-Graduação em Psicopedagogia, só não conseguiu pegar o certificado da Pós-graduação porque ainda não recebeu o diploma, assim como as outras professoras colaboradoras da presente pesquisa. Ela atua na turma da educação Infantil, está com 23 anos de docência. Mostrou-se muito feliz por ter concluído o curso e apesar de ter enfrentando muitos problemas durante o estudo, diz ser encantada pela Educação Infantil, e que passaria por tudo novamente se fosse preciso. Uma característica desta colaboradora foi o prazer demonstrado durante a realização da entrevista de estar em sala de aula e ser querida por seus estudantes, sabendo que a pós-graduação a tornou mais qualificada e realizada.

A professora Laura possui formação em Magistério e Pedagogia, iniciou a pós-graduação, mas não concluiu. Foi encantador vê-la falar sobre a Educação Infantil, pois seus olhos brilhavam quando ela dizia o quanto já gostava e o quanto aprimorou seus conhecimentos sobre. Tem 13 anos com a docência, mas no momento está trabalhando como coordenadora da Educação Infantil, e reconhece a importância de ter concluído a graduação e por ter se permitido estudar, pois sem a atual formação, pedagogia, não estaria ocupando o cargo de coordenadora.

A Professora Luiza também possui formação em Magistério e Pedagogia, atuou nos anos iniciais do Ensino Fundamental, mas no momento está atuando como coordenadora dos anos iniciais. Em suas palavras, percebe-se uma grande frustação por não ter recebido o diploma depois de tantos anos, pois a mesma diz ter se desestimulado muito, reconhecendo a importância que foi ter concluído a graduação, porém, com a insatisfação de ter estacionando um grande período em prol do seu desenvolvimento profissional, uma vez que tinha vontade de fazer pós-graduação e doutorado. Este sonho foi adormecido, mas sua vontade ainda é fazer uma pós-graduação.

\section{ANÁLISE E DISCUSSÃO DOS RESULTADOS DA PESQUISA}

É importante destacar que após as entrevistas narrativas, todas foram transcritas e lidas mais de duas vezes, com intenção de identificar as unidades de sentidos. Com efeito, emergiram as categorias de análises, a seguir: compreensão acerca do desenvolvimento profissional docente; conquistas da formação na atuação docente e perspectivas de novas conquistas no desenvolvimento profissional. 
$\mathrm{Na}$ primeira categoria, "Compreensão acerca do desenvolvimento profissional docente", destacamos as seguintes falas das colaboradoras da pesquisa:

[...] antes nós tínhamos uma visão de desenvolvimento profissional e após a Plataforma Freire passamos a visualizar numa outra dimensão como realizar novas práticas na perspectiva do que aprendíamos no decorrer do curso [...] foi de grande importância para nosso desenvolvimento educacional [...] o que é gratificante, o que é relevante, contribuiu até para minha vida pessoal e profissional (Professora Chica, 2019).

Desenvolvimento profissional é quando nos propomos a fazer cursos; principalmente a graduação, que possa ainda, estar nos qualificando profissionalmente e que possamos estar sempre crescendo. [...] depois da graduação a visão de professor passou a ser outra, ampliou e muito o crescimento profissional, além de ter crescido também a vontade de desenvolver um trabalho ainda maior, o prazer pela sala de aula só expandiu. (Professora, Laura, 2019)

O desenvolvimento profissional é a questão de estudar, capacitar-se, fazer pós-graduação. Acredito que participar de formação continuada vai se desenvolvendo cada vez mais, e ler bastante também é uma ferramenta importante para que esse desenvolvimento aconteça, pois a cada dia as coisas mudam, atualizam [...] Nós aprendemos muito na faculdade [...] a prática acaba mudando com a gente, acabamos aprendendo novas práticas, novas metodologias, novas formas de ensinar, até mesmo como aprender com o próprio aluno [...] então isso foi acontecendo ao longo da formação que se tornava uma troca de experiência significativa para a formação. (Professora, Luiza, 2019).

O desenvolvimento profissional ocorre quando você se propõe a estar estudando, articulando a teoria com a prática [...] o que a gente aprendia na Parfor praticava em nossos trabalhos e via resultados satisfatórios que enriqueceram a formação [...] antes de entrar na Parfor já planejávamos, mas depois dela eu credito que o conhecimento adquirido mudou para melhor [...]. (Professora, Maria, 2019).

As colaboradoras da pesquisa são unânimes em reconhecer que o contexto da formação no PARFOR foi condição imprescindível para o processo de desenvolvimento profissional, salientando a necessidade de efetivar diferentes leituras, cursos, pós-graduações, ou seja, participar de uma formação continuada, com vistas a mobilizar alteração na prática pedagógica, incorporando novas metodologias e novas possibilidades de aprendizagens dos estudantes. Outrossim, salientaram, ainda, a relevância que as partilhas de experiências tiveram e têm no processo de formação docente.

Como aponta (Ramalho, et.al 2014, p.56) "O professor deve passar por um processo de formação". Nessa perspectiva Day (2001, p.24) salienta que "adquirir as qualificações adequadas para se ser professor sempre foi uma condição necessária, embora insuficiente, para se ter êxito como profissional ao longo de toda uma carreira. " Acredita-se que o professor deve estar em constante atualização, ou seja, em processo de autoformação, atualizando-se para dar o melhor de si, não se limitando apenas na formação apreendida ao logo da sua graduação. Ramalho et.al (2004 p.84) ainda reitera que: "as competências no geral, desenvolvem-se desde a formação inicial para a vida profissional na forma de uma espiral ascendente."

Assentindo com Ramalho et.al. (2014, p.65) "o desenvolvimento profissional do professor faz parte de um projeto de desenvolvimento profissional da instituição na qual ele desenvolve sua atividade profissional". É nítido aquiescer que o professor, apesar de autônomo, trabalha na perspectiva de satisfazer, ou seja, seguir um modelo desejado por um grupo maior que leve a identidade da instituição em que está inserido, e a depender de seu desenvolvimento que a escola perceberá se o educador é ou não um bom profissional, se respondeu ou não as suas expectativas.

De acordo com a narrativa da colaboradora, formar-se profissionalizado é um processo contínuo que não acontece rapidamente, pois para ser um bom profissional da educação é preciso passar por pequenas etapas de aprendizagens. Logo, são as formações adquiridas ao longo da carreira que farão o profissional se tornar um destro com maior qualificação.

Na segunda categoria intitulada "Conquistas da formação na atuação docente", as colaboradoras da pesquisa revelaram as seguintes falas:

A partir do Parfor obtive outra concepção do que de fato é a educação, como é ensinar, principalmente a educação infantil que ampliei positivamente, rigorosamente, gostei bastante [...] minha maior e melhor conquista sem dúvidas tem sido concluir a graduação, obter minha formação. (Professora, Chica, 2019)

$\mathrm{Na}$ educação infantil eu pude notar o desenvolvimento das crianças ligadas as teorias que estudamos na PAFOR e sem dúvida foi uma experiência maravilhosa [...] primeiro que não imaginava que pudesse fazer uma graduação alguma vez, e foi na PAFOR que essa oportunidade foi realizada em minha trajetória enquanto professora da rede básica [...] se não fosse minha formação em Pedagogia da PAFOR, não estaria ocupando o cargo de coordenadora da educação infantil aqui na secretária de educação.” (Professora, Laura, 2019) 
[...] de verdade, meu maior deslumbre em minha carreira é quando um aluno aprende a ler, quando começa o ano letivo por exemplo, não tem domínio da leitura; escrita, mas depois com o auxílio do professor começa a desenvolver-se, para mim isso é a maior conquista na minha carreira docente. " (Professora, Luiza, 2019).

[...] antes de ingressar na PAFOR nós já planejávamos bem as nossas aulas, mas melhoraram. Pois, o que aprendemos foi de grande importância para nosso desenvolvimento em sala de aula, os jogos matemáticos foram de grande valia para meu aprendizado e foi uma experiência singular na minha vida enquanto estudante e educadora, podendo inovar de maneira significativa, deixando de lado o ensino tradicional que conhecíamos e aplicávamos. (Professora, Maria, 2019).

Diante das falas das colaboradoras da pesquisa, pudemos perceber o quanto a formação no Parfor contribuiu com conquistas pessoais e profissionais, dentre as quais destacamos: a conclusão da formação, planejamento inovador das aulas, aquisição de novas metodologias, percepção do desenvolvimento dos estudantes em face das novas concepções e atitudes na prática pedagógica, promoção na carreira. Com efeito, é importante destacar que "o professor não é mais um técnico que executa os procedimentos vindos de uma 'racionalidade técnica', e sim sujeito construtor da sua profissão. " (RAMALHO, et.al p.37, 2014) com isso, é percebível que o professor é construtor do conhecimento, ele deve se tornar profissional em sua formação quando percebe em si a capacidade e importância da sua profissão no sentido de transformar realidades vindas à sua direção, que, por sua vez, não utilizam meios tecnicistas, mas promovem a aprendizagem estando em suas mãos uma parte importante para a transformação mentalidade, com vistas a provocar a reivindicação de mudanças sociais.

Neste sentido, necessitamos acreditar e perseguir a lógica defendida por Nóvoa (2009, p.22) quando ele enfatiza que "a aprendizagem ao longo da vida justifica-se como direito da pessoa e como necessidade da profissão, mas não como obrigação ou constrangimento. " Diante disso, o processo de qualificação tende a ser buscado pela individualidade de cada um, pelo desejo de querer, qualificar-se, não tornando um acúmulo de formações que lhes trará problemas futuros, como desgaste emocional. Ou seja, cada um em sua singularidade desenvolverá continuamente até quando achar necessário.

Diante disso, os autores (RAMALHO, 2004.et al. p.102) dizem que "a formação do professor como profissional de perfil amplo deve garantir uma sólida formação teórica, como ferramenta de reflexão, de crítica e construção da prática para a participação consciente no desenvolvimento de projetos profissionais, sociais e individuais. " Com isso, vale ressaltar que a formação perpassa por caminhos longos e de autonomia que encorajam o profissional a garantir sua identidade ao longo da vida, até porque não é uma tarefa fácil, mas que demarca historicamente durante sua caminhada, o desenvolvimento de suas práticas. Ou seja, não basta o profissional ser enraizado de práticas as quais não são sustentadas pelo uso das teorias, o que é perceptível é que a teoria seja primordial em qualquer instância, atrelada às práticas.

Em contribuição ao que foi citado anteriormente, Gatti e Barreto (2009. p.232) ressaltam q

\footnotetext{
As novas condições de trabalho docente exigem mais dos professores no ato de ensinar, exigem qualidades e atitudes pessoais como interesse, paixão, paciência, vontade, convicções, criatividade em outras não possíveis de serem padronizadas, tampouco desenvolvidas em cursos e capacitações formais.
}

Como dito, nessas novas condições de trabalho, esforços serão mais exigidos dos professores, e isso não é adquirido nos cursos de capacitações nem é padronizado, mas depende unicamente de cada professor, pois é algo pessoal e particular, são questões que demarcam a identidade e o querer fazer de cada indivíduo, não partindo apenas da formação que se tenha. Para colaborar com os comentários das professoras, Day (2000, p.17) reitera que "os professores aprendem naturalmente ao longo de cada carreira. Contudo, a aprendizagem baseada apenas na experiência irá, em última análise, limitar o seu desenvolvimento profissional" (DAY, p.17).

Apesar das experiências serem muito importantes, vale salientar que não basta apenas boas experiências para a formação desse profissional (professor), mas que haja formação e qualificação, uma vez que o profissional tem que estar ancorado em referenciais que lhe sustentem. Com isso, a qualificação é de grande valia para a formação desse profissional; não é dizer que as experiências não são importantes, mas ressaltar que somente elas não sustentam a profissionalização.

$\mathrm{Na}$ terceira categoria "Perspectivas de novas conquistas no desenvolvimento profissional", foram elencadas as falas a seguir das participantes:

Sinceramente, não almejo fazer outra graduação, nem pós-graduação. Mas, sempre estou me atualizando participando dos cursos que o município oferece, dentre outros que surgem. (Professora, Chica, 2019). 
Comecei a fazer a pós-graduação em Educação Infantil, mas foi interrompida por conta de não estar com o diploma da graduação em mãos, e isso causaria problemas futuros, como alguns colegas estão correndo, de até mesmo não receber o certificado da pós [...] mas ainda pretendo fazer minha pós-graduação em educação infantil, área que sou apaixonada, assim que receber o certificado de graduada. " (Professora, Laura, 2019).

A pós-graduação ainda não fiz porque não estou com o diploma em mãos, mas faço formação continuada, teve o curso do PACTO que a prefeitura proporcionou, e outros que surgiram e surgem. Cheguei a começar a fazer uma pós durante o curso, porém depois da graduação, acabei sendo desestimulada pela questão do diploma [...] a sensação de ter o nível superior é muito bom, maravilhoso, a pessoa fica com uma vontade imensa de aprender mais e mais; tinha um sonho de chegar ao doutorado. Mas esse sonho foi diminuído por conta desse transtorno que estar sendo para pegar o diploma de graduada em Pedagogia [...] $\mathrm{O}$ desejo de estudar mais, acabou sendo adormecido. Somente após o reconhecimento do curso, e que pegar o diploma que vou tomar essa a decisão quanto a continuidade aos estudos." (Professora, Luiza, 2019).

Desde a graduação que tenho a vontade de estudar Libras, e agora que estou sendo cuidadora de duas crianças especiais em uma escola municipal, estou achando muito interessante, pois vejo que eles dependem muito do professor, e temos que estar conectados a eles a todo o momento, para assim realizar um bom trabalho, com isso penso em fazer uns pós para trabalhar com crianças que tenham autismo. Quero fazer libras como curso de pós-graduação, pois continuo sendo apaixonada pela língua de sinais. " (Professora, Maria, 2019)

As falas das professoras demonstram vontade em prosseguir nos estudos, sobretudo através da pós-graduação, revelando que o desejo de prosseguir em cursos de especializações está ancorado a novas conquistas que planejam alcançar. Contudo, também denunciam de forma emocionada sobre a frustração por não terem acesso, até o momento atual, ao diploma de graduação em Pedagogia, pois essa situação tem impedido a continuidade desses novos sonhos a serem conquistados. Apenas a professora Chica (2019) não explicitou o desejo de novas conquistas. Para Amorim (2018, et.al. p.33):

O termo desenvolvimento profissional docente tem mobilizado pesquisadores, professores e estudantes de diferentes contextos, em face da recorrente busca de profissionais de educação pela continuidade de seus estudos e reflexões acerca do processo de ensino e aprendizagem antes, durante e depois da formação docente. No entanto, sabe-se que a compreensão desse processo apresenta diferentes conceitos e concepções.

Entende-se que o desenvolvimento profissional docente tem criado reflexões aos estudantes e profissionais da educação. Contudo, os aspectos atrelados ao processo do desenvolvimento profissional docente demonstram que esse profissional, para se desenvolver integralmente como um profissional transformador, depende diretamente do seu emocional, das condições de trabalho, remuneração e da qualidade de ensino. "Os professores estão condicionados por uma variedade de factores, tais como: as crenças e valores pessoais, os objetivos da aula, as condições da sala de aula, os recursos, o comportamento dos alunos, o número de alunos, etc. (DAY, 2001, p.62) ".

Portanto, é concordável que os professores passam por contextos difíceis em sala de aula, que acabam acarretando, ou até mesmo influenciando no não avanço dos alunos, uma vez que essas salas de aula não estejam propícias para a promoção da aprendizagem como posto, dando ênfase em alguns pontos que podem ser prejudiciais. Cabe também ao professor estar buscando melhorias que influenciarão em seu desenvolvimento profissional, sobretudo na qualidade do seu trabalho pedagógico.

É nítido perceber a importância da formação continuada para o professor. Por isso ele que tem que buscar meios de prosseguir continuamente, uma vez que a educação não para, está em evolução permanentemente e o papel do educador é ressignificar suas posturas e aprendizados a cada dia. Desse modo, Gatti e Barreto (2009, p.226) apontam que "do professor mais avançado na carreira se poderia esperar um repertório de estratégias diversas que o auxiliem em sua prática e um investimento em ampliar e diversificar esse repertório."

Logo, cabe ao profissional buscar sempre maneiras de remanejar suas atitudes e buscar diferenciar suas práticas quando já não mais fazem sentido para um determinando contexto, participar de formações que tenham novas visões do modelo que já lhe é convencional em suas práticas docentes, para assim tornar o ensino cada vez mais dinamizado, com qualidade e significativo.

\section{CONSIDERAÇÕES FINAIS}

Diante das narrativas ora apresentadas, levando em consideração as experiências e lugares de fala de cada colaboradora, podemos compreender que o desenvolvimento profissional extrapola o âmbito 
educacional. Uma vez que desenvolver-se profissionalmente potencializa cada vez mais as habilidades apreendidas no decorrer da carreira, podendo assim desenvolver um trabalho de qualidade.

A atuação dessas colaboradoras em seus trabalhos foram ressignificadas a partir do seu desenvolvimento profissional adquirido na graduação e também fora dela, com pós-graduação, cursos de especialização, e até mesmo a troca de experiências uma com as outras. Percebe-se o reconhecimento e gratificação nas narrativas por terem feito uma graduação, enquanto professoras com magistério que não possuía nível superior, e com um pouco mais de esforço e dedicação terem realizado um sonho que adormecido por algumas delas.

Ficou evidenciado que o Parfor teve grande influência positiva para a educação e desenvolvimento profissional dessas profissionais. As professoras tiveram seus momentos de euforia, de desespero, de desestímulo, mas com perseverança, estudo e paciência foram contempladas com a conclusão do curso e possibilidades de melhores empregos, como é o caso das colaboradoras que trabalham no setor de coordenação geral do município Serrinha-Ba, no Território do Sisal, na educação infantil e no ensino fundamental I.

Isso não quer dizer que quem não está trabalhando na área de coordenação não chegou a conquistar um melhor lugar, pois cada um deve estar no lugar que desejar. Utilizar as melhores práticas e desenvolver um bom trabalho é fruto de um profissional que se desenvolveu profissionalmente e entendeu qual é o seu papel enquanto cientista da educação, que assim, melhore, remaneje e possibilite novas práticas dia após dia.

Diante disso, se faz necessário que toda a sociedade seja atualizada e conscientizada a perceber a importância da formação continuada dos profissionais da educação e o papel que estes podem exercer no meio social. É veementemente necessário que os profissionais pedagogos tenham acesso às novas experiências e realizações profissionais.

\section{REFERÊNCIAS}

AMORIM, Ivonete Barreto de. Desenvolvimento profissional docente: perspectivas de professoras egressas do Curso de Pedagogia do PAFOR. In: AMORIM, Ivonete Barreto de; SILVA, Sandra Célia Coelho Gomes; SOUZA, Sueli Ribeiro Mota. (Org.) Educação em Perspectivas: Interfaces do Saber Insurgente - Curitiba: CRV, 2018. (p.31- 46).

DAY, Christopher. Os professores enquanto investigadores. Compreender $\mathrm{O}$ desenvolvimento profissional dos professores: experiência, saber-fazer Profissional e competência. As condições de trabalho dos professores: as salas De aula, as culturas e a liderança. In: DAY, Christopher. Desenvolvimento Profissional de Professores: os desafios da aprendizagem permanente. Portugal: Porto, 2001. p.47-144.

Ser professor desenvolver-se como profissional, in: Desenvolvimento Profissional de Professores: os desafios da aprendizagem permanente. Porto - Portugal, 2001. P.15-45.

GATTI, Angelina Bernadete. BARRETO, Elba Siqueira de Sá. A formação continuada em questão. In: GATTI, Angelina Bernadete. BARRETO, Elba Siqueira de Sá. Professores do Brasil: impasses e desafios - Brasília, UNESCO-2009. (p.199-234).

MINAYO, Maria Cecília de Souza. Pesquisa social: teoria, método e criatividade. 17 ed. Petrópolis (RJ): Vozes, 2000.

NÓVOA, António. Professores: o futuro ainda demora muito tempo? In: Nóvoa, António. Professores imagens do futuro presente. Lisboa: EDUCA, 2009, p.09-24.

PORTELA, Regina Lúcia dos Santos. Os ministérios de Clarice: narrativas de professoras egressas da primeira turma do curso de Licenciatura em Pedagogia do Parfor UFBA sobre a formação. $2019.137 \mathrm{f}$. Dissertação (Pós-graduação) Programa de Pós-Graduação em Educação da Faculdade de Educação da Universidade Federal da Bahia. 2019.

RAMALHO, Betânia Leite; NUÑEZ, Isauro Beltrán; GAUTHIER, Clermont. Um Quadro Paragmático para a mudança a propósito da formação e da Profissionalização docente inicial. In: Formar o professor, profissionalizante o ensino: perspectivas e desafios. $2^{\circ}$ ed. Porto Alegre: Saulina, 2014. p. 17-47 
RAMALHO, Betânia Leite; NUÑEZ, Isauro Beltrán; GAUTHIER, Clermont. Para saber o rumo da mudança: a propósito de um modelo profissional, In: Formar o professor, profissionalizante o ensino: perspectivas e desafios. $2^{\circ}$ ed. Porto Alegre Saulina, 2014. p.97-132.

SILVA, Thayane Mayara Carvalho. Repercussões da formação e da não formação de professores em suas práticas pedagógicas. 2015. 60 f. monografia- Universidade do Estado da Bahia, Serrinha-BA, 2015 .

Informações sobre os autores:

EJS: Graduanda em Pedagogia pela Universidade do Estado da Bahia. Bolsista de Iniciação Científica (CNPQ). Membro do Grupo de Pesquisa Educação, Políticas Públicas e Desenvolvimento Social.

IBA: Pós-Doutora em Educação e Contemporaneidade pelo PPGEduC/INEB. Doutora em Família na Sociedade Contemporânea pelo Programa de Pós-graduação da Universidade Católica do Salvador UCSAL. Professora Adjunta da Universidade do Estado da Bahia Campus XI. Professora e Vice Coordenadora do Mestrado Profissional em Intervenção Educativa e Social (MPIES). Líder do grupo de pesquisa Educação, Políticas Públicas e Desenvolvimento Social (EPODS) - UNEB/CAMPUS XI

SCCGS: Pós doutora em Educação e Contemporaneidade pela Universidade do Estado da Bahia (UNEB); Doutora em Ciências da Religião (PUC-GO). Coordenadora do Mestrado Profissional em Intervenção Educativa e Social (MPIES - UNEB -DEDC - Campus XI - Serrinha), Professora Adjunta da Universidade do Estado da Bahia DEDC - Campus XII - Guanambi

Contribuição dos autores: EJS; IBA; SCCGS: conceptualização, captação de recursos, supervisão, redação. 